\title{
APLICAÇÃO DE TRATAMENTO ESTATÍSTICO MULTIVARIANTE EM DADOS GEOQUÍMICOS DE SOLO NO MAPEAMENTO GEOLÓGICO NA PROVINNCIA DE CARAJÁS (ALVO 2 - CORPO 4)
}

\author{
CÂNDIDO AUGUSTO VELOSO MOURA*
}

\begin{abstract}
A geochemical soil survey was carried out in the Alvo 2 - Corpo 4 area of the Carajás Mineral Province, Pará, Brazil. Soil sample elements were collected and analysed in order to determine, for each one of them, the degree of concentration of the following chemical elements: $\mathrm{Fe}, \mathrm{Al}, \mathrm{Mg}, \mathrm{Mn}, \mathrm{Ti}, \mathrm{Co}, \mathrm{Ni}, \mathrm{V}, \mathrm{Cu}$, and $\mathrm{Zn}$. Thereafter, multivariant statistical techniques were employed to process the data, that are known as cluster analysis and discriminant analysis. The former algorithm was applied in order to classify the element of the soil sample into geochemically homogeneous group that could be correlated with underlying rocks. A discriminant analysis was then performed to statistically evaluate the distinctiveness of groups arrived at, and at the same time to define those chemical elements which were most determinant throughout the discriminatory process. Cluster analysis classified the soil sample elements into eight homogeneous groups that are perfectly correlated with underlying rocks. Discriminant analysis showed that results of the clustering are good, and only titanium and zinc do not play an important role in discriminating the groups arrived at. The results obtained show that the multivariant statistical processing of geochemical data can be used successfully as a useful tool when mapping the geology of tropical areas.
\end{abstract}

INTRODUÇÃo Na Região Norte do Brasil, o clima tropical reinante favorece o intemperismo químico das rochas e dá origem, geralmente, a espessas camadas de solo que dificultam a obtenção de informações geológicas durante a execução de trabalhos de mapeamento e prospecção. Como conseqüência, faz-se necessário lançar mão de técnicas indiretas para auxiliar na realização desses trabalhos. Em determinados casos, o tratamento estatístico multivariante de dados geoquímicos de solo pode ser utilizado como uma ferramenta auxiliar na identificação de rochas geoquimicamente distintas e cobertas por uma espessa camada de solo. Uma pesquisa nesse sentido foi realizada por Silva (1980), que estudou as variações na composição química do solo na região da Serra dos Carajás e conseguiu estabelecer uma estreita relação entre as diferentes litologias subjacentes e os solos correspondentes.

Neste trabalho é realizada uma avaliação da aplicação do tratamento estatístico multivariante de dados geoquímicos de solos como uma técnica auxiliar ao mapeamento geológico em áreas tropicais. A área do trabalho situa-se na Província Mineral de Carajás, no Estado do Pará, Brasil, e é denominada Alvo 2 - Corpo 4 pela Rio Doce Geologia Mineração (Docegeo), que nela executou estudos geológicos e geoquímicos (Fig. 1). $\mathrm{O}$ conhecimento geológico existente e a facilidade de infra-estrutura gerada pela atuação dessa empresa de mineração foram determinantes para a escolha do Alvo 2 - Corpo 4 como área de trabalho.

Realizou-se a amostragem de solo e os elementos amostrais foram analisados para 10 elementos químicos $(\mathrm{Al}, \mathrm{Fe}$, $\mathrm{Mg}, \mathrm{Mn}, \mathrm{Ti}, \mathrm{Ni}, \mathrm{Co}, \mathrm{V}, \mathrm{Cu}$ e $\mathrm{Zn}$ ). Os resultados analíticos foram tratados estatisticamente pela técnica multivariante, conhecida como análise de agrupamentos, com o objetivo de classificar os elementos amostrais do solo em grupos geoquimicamente homogêneos e correlacionáveis às rochas subjacentes. Como para essa técnica não existem testes estatísticos que quantifiquem a precisão dos resultados alcançados, aplicou-se a análise discriminante com a finalidade de avaliar os agrupamentos obtidos e, paralelamente, verificar que elementos químicos mais contribuíram na separação dos diversos grupos de solos.

Os cálculos estatísticos foram realizados no computador Decsystem 1091 do Serviço de Estatística e Computação da Universidade Federal do Pará (SECOM-UFPa). Referências acerca dos programas utilizados para o tratamento dos dados são fornecidos no decorrer do texto.

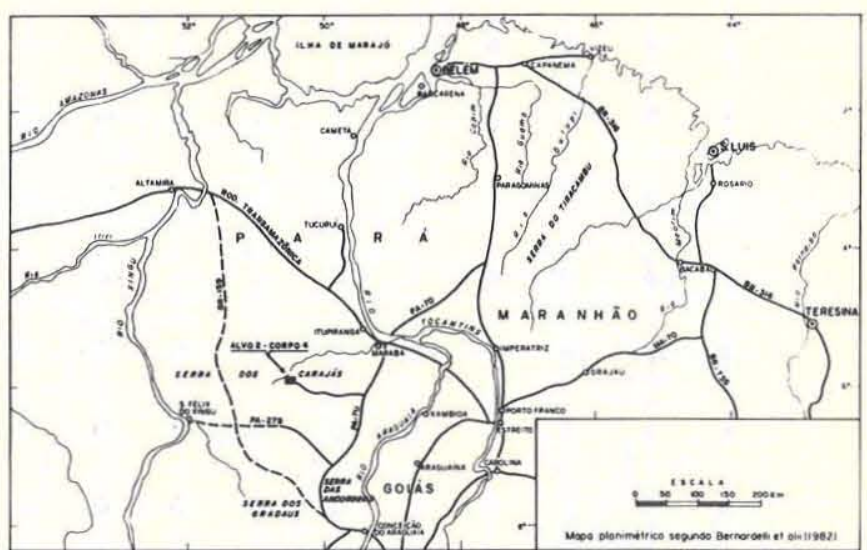

Figura 1 - Mapa de localização do Alvo 2 - Corpo 4

GEOLOGIA DA AREA A área objeto de estudo (Alvo 2 - Corpo 4) encontra-se coberta por uma espessa camada de solo e saprólito, com cerca de $50 \mathrm{~m}$ ou mais de espessura em alguns locais. Os afloramentos são escassos e limitam-se às proximidades das drenagens, e as mais significativas informações sobre a rocha são obtidas pelos testemunhos das sondagens efetuadas pela Docegeo.

O Alvo 2 - Corpo 4 é constituído por uma faixa, topograficamente mais elevada, de anfibólio xistos, que separa geograficamente rochas metassedimentares de rochas bási- 
cas cuja continuidade é truncada por um corpo de rocha com antofilita e cordierita (Fig. 2).

Anfibólio xistos é um termo genérico aqui empregado para designar uma seqüência vulcano-sedimentar metamorfisada no fácies anfibolito composta de hornblenditos, quartzo-hornblenda-cumingtonita xisto, quartzo-cumingtonita xisto com níveis granatíferos, biotita-hornblenda xisto, formação ferrífera bandada etc. $\mathrm{O}$ corpo de rocha com antofilita e cordierita, além desses dois minerais, possui quantidades variáveis de plagioclásio (aproximadamente $\mathrm{An}_{31}$ ), biotita, clorita e opacos. Sob a denominação metassedimentos, reúnem-se metarenitos, metarcósio, metagrauvacas, metassiltitos, metargilitos e formação ferrífera.

Esses conjuntos de rochas acima descritos foram agrupados por Hirata et al. (1982) numa única unidade denominada ainda informalmente Seqüência Salobo-Pojuca, sendo que os metassedimentos seriam rochas de grau metamórfico mais baixo. Os autores situam crono-estratigraficamente a Seqüência Salobo-Pojuca no Proterozóico Inferior.

As rochas básicas, cuja composição mineralógica original foi modificada possivelmente por ação hidrotermal, possuem variação granulométrica bem ampla, apresentando textura de fanerítica a afanítica. Mineralogicamente são constituídas por anfibólio da série tremolita-actinolita, plagioclásio $\left(\mathrm{An}_{42-55}\right)$, epídoto, clorita $\mathrm{e}$, como acessórios, titanita, opacos e eventualmente quartzo.

OBTENÇÃO DOS DADOS GEOQUIMICOS Os trabalhos de amostragem no Alvo 2 - Corpo 4 consistiram na coleta de 171 elementos amostrais do solo numa área de aproximadamente $2 \mathrm{~km}^{2}$. As estações de coleta dispõem-se quadraticamente distantes $100 \mathrm{~m}$ entre si, ao longo de 19 perfis transversais à linha base C4-00 de direção N36W. O material foi coletado a $40 \mathrm{~cm}$ de profundidade com o auxílio de uma escavadeira manual conhecida como "boca de lobo". Na tentativa de obter-se uma representatividade significativa do material amostrado, foi coletado cerca de $1 \mathrm{~kg}$ de solo por amostra.

Os elementos amostrais do solo foram secos em estufa a $95^{\circ} \mathrm{C}$, desagregados e peneirados. A fração menor que $2 \mathrm{~mm}$ sofreu quarteamento, trituramento até à fração menor que $0,063 \mathrm{~mm}$ e posterior homogeneização. 0 material homogeneizado sofreu abertura a quente com uma mistura de $\mathrm{HF}$ e $\mathrm{HClO}_{4}$ na proporção 2:1 e posterior adição de $\mathrm{HCl}$ (Bock 1972).

As soluções obtidas foram analisadas para 10 elementos químicos ( $\mathrm{Fe}, \mathrm{Al}, \mathrm{Mg}, \mathrm{Mn}, \mathrm{Ti}, \mathrm{Ni}, \mathrm{Co}, \mathrm{V}, \mathrm{Cu}$ e $\mathrm{Zn}$ ), utilizando-se o espectrômetro de absorção atômica modelo FMD-4 de fabricação Carl Zeiss. As análises foram realizadas segundo as especificações contidas no manual do aparelho.

Para um melhor controle dos dados analíticos (Apêndice 1), a cada três transversais amostradas repetia-se a análise da última. Os resultados duplicados foram considerados bons para o propósito do trabalho. Foram obtidas variações máximas de $5 \%$ para os elementos $\mathrm{Al}, \mathrm{Mg}$ e $\mathrm{Zn}$, e menores que $3 \%$ para os demais (Moura 1982).

ANĀLISE DE AGRUPAMENTOS A análise de agrupamentos é uma técnica estatística multivariante que utiliza a similaridade entre indivíduos para classificá-los

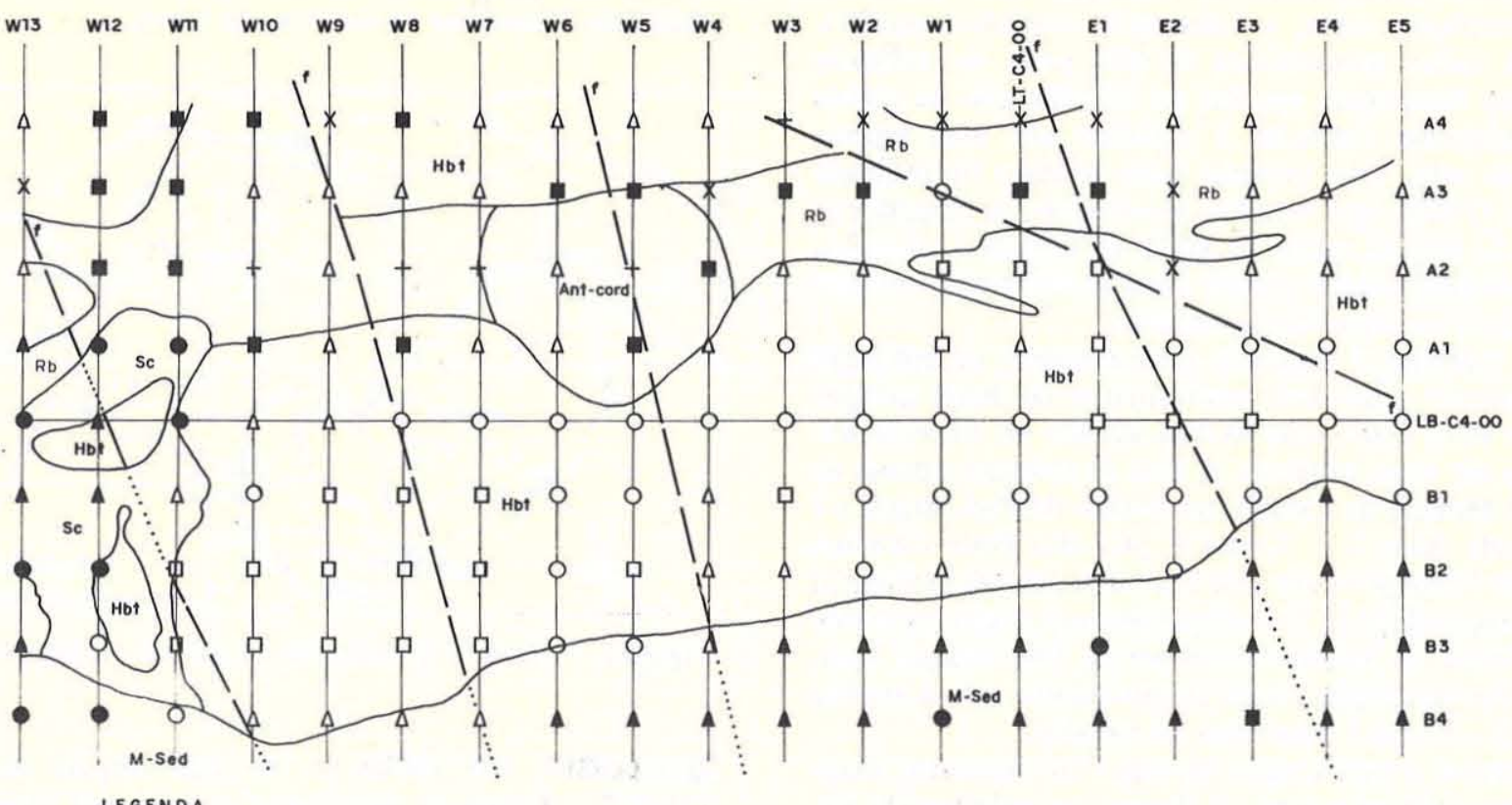

LEGENDA

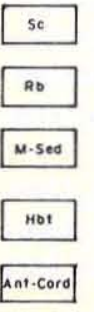

ALUVIOES, DEPositos de AREIA E ARENITOS IMPUROS
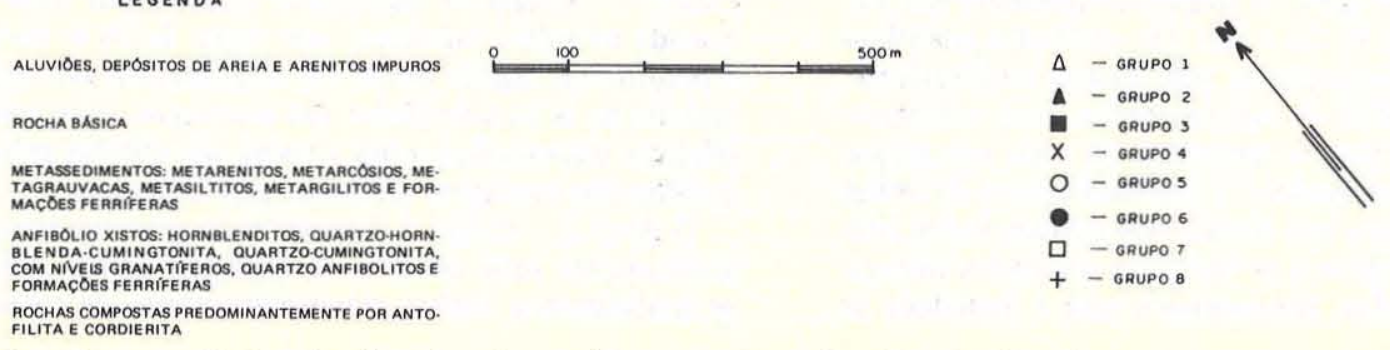

Figura 2 - Mapa geológico do Alvo 2 - Corpo 4, mostrando a classificação dos elementos amostrais nos seus respectivos gru pos (mapa elaborado pela Docegeo) 
hierarquicamente em grupos, mais ou menos homogêneos, considerando-se simultaneamente todas as variáveis para cada indivíduo.

As medidas do grau de similaridade normalmente utilizadas são o coeficiente de distância euclidiana e o coeficiente de correlação de Pearson. $\mathrm{O}$ coeficiente de distância é mais usado quando se deseja estabelecer o grau de similaridade entre objetos enquanto o coeficiente de correlação é mais útil para medir o grau de similaridade entre variáveis. $\mathrm{O}$ primeiro caso é conhecido como método $\mathbf{Q}$ e o segundo, como método $\mathbf{R}$ de análise de agrupamentos (Sobreiro Neto \& Campos 1980, Roy 1981).

Para desenvolver a análise de agrupamentos, os dados são dispostos inicialmente numa matriz ' $\mathbf{n}$ vezes $\mathbf{m}$ ", em que n é o número de objetos e $\mathrm{m}$, o de variáveis. Posteriormente, constrói-se uma matriz simétrica de similaridade, entre todos os pares possíveis de objetos, a partir do cálculo dos coeficientes de distância (método Q), ou entre os pares possíveis de variáveis, pelo cálculo do coeficiente de correlação (método $\mathbf{R}$ ). Finalmente, os objetos ou as variáveis são organizados segundo níveis hierárquicos de similaridade, de tal modo que cada ciclo de agrupamentos obedeça a uma ordem sucessiva no sentido de decréscimo de similaridade. Esse agrupamento hierárquico é representado em duas dimensões pelo diagrama dendrítico denominado dendograma (Landim 1976).

Aplicação do método de agrupamento A análise de agrupamentos, método $\mathbf{Q}$, foi empregada para classificar os elementos amostrais do solo em grupos geoquimicamente homogêneos com base nas similaridades de suas composições químicas. Utilizando a linguagem estatística, diz-se que os elementos amostrais do solo representam os objetos, ou observações, ou casos, enquanto os elementos químicos representam as variáveis.

Foram utilizadas como variáveis os seguintes elementos químicos: $\mathrm{Fe}, \mathrm{Al}, \mathrm{Mg}, \mathrm{Mn}, \mathrm{Ti}, \mathrm{Co}, \mathrm{Ni}, \mathrm{V}, \mathrm{Cu}$ e $\mathrm{Zn}$. Logo, a análise de agrupamentos foi governada pelo teor desses elementos químicos em cada um dos elementos amostrais do solo. A distribuição de freqüência dos elementos analisados, comumente é assimétrica positiva (Moura 1982). Entretanto não se procurou transformar matematicamente os dados originais com a finalidade de obter-se uma distribuição normal porque a análise de agrupamentos é uma técnica que dispensa tal medida (Parks 1966).

Os cálculos estatísticos foram realizados utilizando o programa Cluster em linguagem Fortran IV (Davis 1973). Este programa calcula os coeficientes de distância, executa o agrupamento pareado igualmente ponderado (W.P.G.M.)* e, finalmente, imprime a classificação hierárquica graficamente, o dendograma. Foi incluída no programa Cluster a sub-rotina Stand (Davis op. cit.) para padronizar os dados e com isso retirar a influência que as diferentes unidades de medidas porventura exercessem no cálculo dos coeficientes de distância.

Interpretação dos resultados $\mathrm{Na}$ interpretação do dendograma, a delimitação dos diversos agrupamentos foi ba- seada não apenas no valor dos coeficientes de distância mas também foi considerada a distribuição dos elementos amostrais no mapa geológico. Portanto, o agrupamento resultante é fruto da interação dendograma-mapa geológico. A figura 3 mostra a delimitação desses grupos no dendograma enquanto a figura 2 registra a localização de cada elemento amostral e o respectivo símbolo do grupo a que pertence no mapa geológico. Os elementos amostrais do solo do Alvo 2 - Corpo 4 foram classificados em oito grupos̊ distintos, relacionados da seguinte maneira com a unidade rochosa subjacente:

- Grupo 1,5 e 7 - Solo desenvolvido sobre os anfibólio xistos.

- Grupo 2 - Solo desenvolvido sobre os metassedimentos.

- Grupo 3 e 8 - Solo desenvolvido sobre as rochas básicas.

- Grupo 4 - Solo desenvolvido próximo ao contato das rochas básicas com anfibólio xistos.

- Grupo 6 - Solo desenvolvido sobre aluviões.

$\mathrm{Na}$ faixa central de anfibólio xistos, formaram-se dois agrupamentos geoquimicamente distintos (grupos 5 e 7), que podem estar refletindo a existência de diferenças composicionais significativas dentro desta unidade litológica (Fig. 2). Essas diferenças haviam sido constadas, anteriormente, por Guimarães \& Townend (1979), Guimarães \& Amaral (1980) e Hirata et al. (1982), que reconheceram anfibólio xistos com origem em rochas vulcânicas básicas e rochas sedimentares químicas. Entretanto os estudos aqui realizados não permitem que se relacionem os agrupamentos identificados com este ou aquele tipo litológico. $\mathrm{Na}$ parte nordeste da área observa-se um outro tipo de solo geoquimicamente distinto (Grupo 1), desenvolvido também sobre anfibólio xistos (Fig. 2).

O prévio conhecimento da geologia da área ajudou a separar os elementos amostrais que à primeira vista pareciam estar agrupados. Essas separações foram realizadas mediante uma flutuação no valor do coeficiente de distância, seguida pelo exame do mapa geológico. Donde se conclui ser importante uma perfeita integração entre o dendograma e o mapa geológico.

Destaca-se como exemplo dessa interação a discriminação entre os elementos amostrais do solo desenvolvido sobre rochas básicas (Grupo 3) e aqueles sobre rochas metassedimentares (Grupo 2). Considerando-se o valor do coeficiente de distância igual a 1,05 apenas um agrupamento é formado. Entretanto, diminuindo-se o valor desse coeficiente para 0,90 é possível identificar, de maneira eficiente, dois agrupamentos relacionados a esses dois tipos litológicos distintos (Fig. 3).

A comparação entre os agrupamentos obtidos no dendograma com o mapa geológico revela também a localização preferencial dos elementos amostrais classificados no Grupo 4 na zona de contato entre rochas básicas e anfibólio xistos (Figs. 2 e 3).

É bastante curioso o fato de se ter obtido dois agrupamentos significativamente distintos, grupos 3 e 8 , para o

* O primeiro passo do método do agrupamento pareado igualmente ponderado (Davis 1973, Landim 1976) é encontrar os pares de objetos com menor coeficiente de distância na matriz de similaridade, que formarão os centros de agrupamentos. A partir desses pares a matriz de similaridade é recalculada, tratando-se cada par como um elemento singular. Novos coeficientes de distância, entre todos os grupos de objetos não-agrupados, são calculados pela média aritimética. O processo de agrupamentos se repete até que todos os grupos estejam ligados. 


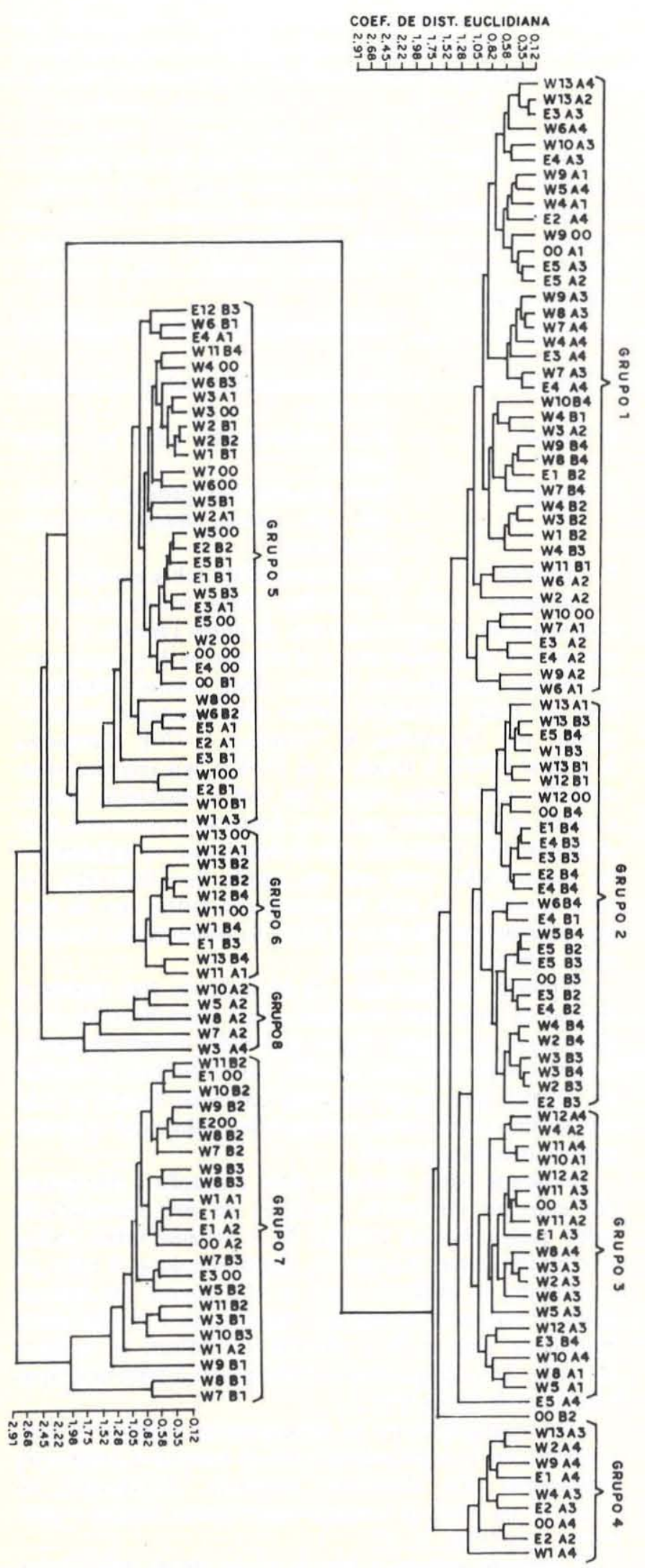

Figura 3 - Dendograma mostrando a classificação dos elementos amostrais com base na análise de agrupamentos.

solo desenvolvido sobre rochas básicas (Figs. 2 e 3). Supõese que isso reflita uma heterogeneidade do meio amostrado, provocada por fatores locais. De fato, os elementos amostrais classificados no Grupo 8, comumente foram coletados nas proximidades das drenagens, onde os afloramentos são evidentes e o solo possui pequenos fragmentos, parcialmente alterados, da rocha-mãe. Por outro lado, os elementos amostrais classificados no Grupo 3 foram coletados num solo em estágio de desenvolvimento mais intenso, típico do horizonte B. Isso vem ressaltar a importância de um controle adequado para garantir a homogeneidade da amostragem.

A escolha das variáveis também influencia a eficiência da análise de agrupamentos. Muitas vezes, as variáveis relacionadas não conseguem exprimir diferenças significativas que possam distinguir perfeitamente grupos de elementos amostrais. A não-distinção geoquímica do solo desenvolvido sobre rochas com antofilita e cordierita, com base nas 10 variáveis utilizadas, pode ser tomada com um exemplo desse fato.

A análise de agrupamentos possibilitou a classificação dos solos em grupos geoquimicamente homogêneos e correlacionáveis com as rochas subjacentes. $\mathrm{O}$ prévio conhecimento da geologia do Alvo 2 - Corpo 4 e o controle na coleta de material evitaram distorções que ocorreriam caso a interpretação dos resultados fosse realizada sem o apoio dos dados de campo. Todavia, como não existem testes que possibilitem avaliar se os agrupamentos obtidos estão estatisticamente corretos, aplicou-se, então, a análise discriminante com este propósito, pois essa técnica multivariante tem a capacidade de verificar se um agrupamento preestabelecido é estatisticamente consistente ou não.

ANÁLISE DISCRIMINANTE A análise discriminante é uma técnica multivariante que permite distinguir estatisticamente dois ou mais grupos de casos entre si, definidos previamente por uma situação particular de pesquisa. Para verificar a distinção entre os grupos, deve ser selecionada uma coleção de variáveis discriminantes que meçam as características pelas quais os grupos são esperados diferir.

A análise discriminante tenta pesar e combinar linearmente as variáveis discriminatórias de modo a maximizar as diferenças estatísticas entre os diversos grupos de casos ou populações. As funções que discriminam os grupos entre si, denominadas funções discriminantes, são matematicamente definidas por:

$$
D_{i}=\sum_{k=1}^{p} d_{i k} \quad z_{k} \quad \text { onde: }
$$

D $_{\mathbf{i}}$ é o escore discriminante de i-ésima função; $\mathbf{d}_{\mathbf{i k}}$ são os pesos dos coeficientes das funções discriminantes; $\mathbf{Z}_{\mathbf{k}}$, os valores padronizados das variáveis; e p, o número de variáveis discriminatórias utilizadas na análise. Em geral, o número máximo de funções discriminantes é um a menos que o número total de grupos. Uma vez derivadas essas funções, é possível alcançar os dois objetivos dessa técnica: a classificação e a análise.

A classificação permite enquadrar casos desconhecidos dentro de agrupamentos previamente estabelecidos. A análise fornece diversas ferramentas para a interpretação dos dados, tais como: 1. os testes estatísticos para medir a importância de uma variável discriminante quando combinada na função; e 2. a interpretação dos pesos dos coeficientes, o que ajuda a identificar as variáveis que mais contribuem para diferir os grupos ao longo de uma determinada função (dimensão).

Maiores considerações acerca dos princípios teóricos da 
análise discriminante, bem como exemplos de sua aplicação, podem ser encontradas em Koch \& Link (1971), Davis (1973) e Klecka (1975), sendo que este último foi a base principal para as considerações acima desenvolvidas.

Aplicação do Discriminant Subprogram O Statistical Package for the Social Sciences (SPSSP), Nie et al. (1975), é um pacote para computação com linguagem própria, que contém exclusivamente programas para cálculos estatísticos, até tratamento estatístico multivariante, para ser aplicado nas Ciências Sociais. Desse pacote utilizou-se o Discriminant Subprogram (Klecka 1975) para a realização da análise discriminante. Os cálculos foram efetuados com as mesmas variáveis utilizadas na análise de agrupamentos.

Com a finalidade de fornecer subsídios para a avaliação da importância relativa de cada função discriminante, o Discriminant Subprogram fornece, para cada função derivada, seus respectivos auto-valores e correlações canônicas associadas (Tab. 1). Na porção direita da tabela são mostrados os valores de lambda segundo Wilk, que é uma medida inversa do poder de discriminação da função, e seus testes chi-quadrado de significância estatística correspondentes. Esses dados indicam que as três primeiras funções são as mais importantes no processo discriminatório. A somatória da porcentagem relativa dos valores dessas três funções perfaz $82 \%$ do total. Logo, qualquer consideração analítica pode ser realizada com base nestas funções sem risco de se cometer erros maiores.

O Discriminant Subprogram fornece também os coeficientes das funções discriminantes (Tab. 2). O valor absoluto dos coeficientes revela a contribuição relativa da variável associada à função. $\mathrm{O}$ sinal na frente dos coeficientes indica apenas se a variável está contribuindo positiva ou negativamente na função.

O Discriminant Subprogram calcula ainda diversos parâmetros estatísticos, sendo que os utilizados neste trabalho são a média e o desvio-padrão para cada grupo e para todos os grupos (Tab. 3). Além disso, fornece a média dos escores discriminantes de cada função para um dado grupo, que representa a centróide desse grupo e, por conseguinte, indica a posição mais típica de um caso desse grupo no espaço definido pelas funções discriminantes (Tab. 4). Quanto maior a diferença entre os valores das centróides dos grupos para uma da função maior a discriminação dos grupos entre si por essa função. Para uma melhor visualização dessa propriedade, foi construído um gráfico em que são localizadas as centróides dos grupos nos eixos definidos pelas três principais funções (Fig. 4).

Um outro recurso importante do Discriminant Subprogram é a tabela de previsão dos resultados. Ela indica o número de casos classificados nos grupos previamente esta- belecidos e a porcentagem correta da classificação desses grupos. Além disso, fornece ainda informações sobre a aceitação do agrupamento pré-estabelecido (Tab. 5).

Interpretação dos resultados Como se viu, a análise discriminante foi aplicada com o objetivo de avaliar estatisticamente a análise de agrupamentos e verificar que variações mais contribuem para o processo de discriminação dos grupos de solos.

A primeira questão é respondida basicamente pela tabela 6. Observa-se que $91 \%$ dos casos estão classificados corretamente, o que mostra uma grande concordância entre o número de casos reais de cada grupo e o número previsto pela análise discriminante. Logo, a classificação dos elementos amostrais do solo do Alvo 2 - Corpo 4 em oito grupos distintos foi estatisticamente aceita pela análise discriminante.

As considerações sobre a importância das variáveis (elementos químicos) no processo discriminatório são feitas com base nas três primeiras funções, as mais significativas para a análise discriminante (Tab. 1). Deve-se analisar cada função separadamente pois a importância de uma variável depende do poder de discriminação da função. É oportuno lembrar que as variáveis mais importantes na discriminação dos grupos são aquelas cujos coeficientes padronizados das funções discriminantes apresentam os maiores valores absolutos e nas quais o sinal de coeficiente indica se as variáveis estão contribuindo negativa ou positivamente na função (Tab. 2).

$\mathrm{Na}$ primeira função, as variáveis mais significativas são $\mathrm{Cu}, \mathrm{Fe}, \mathrm{Mg}, \mathrm{Ni}$, Co e $\mathrm{V}$, sendo que as duas primeiras são as mais importantes. $\mathrm{Cu}, \mathrm{Fe}$ e $\mathrm{Co}$ contribuem negativamente na função enquanto $\mathrm{Mg}$, $\mathrm{Ni} \mathrm{e} \mathrm{V}$ dão uma contribuição positiva. Isto equivale dizer que essa primeira função mede a ausência do $\mathrm{Cu}, \mathrm{Fe}$ e $\mathrm{Co}$ e a presença de $\mathrm{Mg}$, Ni e V nos elementos amostrais. Esses dados sugerem que os altos teores de $\mathrm{Cu}$ e $\mathrm{Fe}$ nos grupos 5 e 7 são determinados para a discriminação desses grupos dos demais. Os diferentes teores de $\mathrm{Cu}$, Co e V contribuem para a discriminação dos grupos 5 e 7 entre si (Fig. 4 e Tab. 3). $\mathrm{O}$ elevado teor de $\mathrm{Mg}$ e a baixa concentração de $\mathrm{Cu}$ e $\mathrm{Fe}$ no Grupo 8 são os principais responsáveis pela pronta discriminação deste grupo pela primeira função (Fig. 4 e Tab. 3). Entretanto, essa função não consegue discriminar satisfatoriamente os grupos 2, 3, 4 e 5 entre si (Fig. 4). Talvez a existência de muitas variáveis (seis ao todo) com poderes de discriminação relativamente equivalentes (Tab. 4) tenha mascarado as diferenças mais significativas entre esses grupos, de sorte que a diferença acentuada por uma variável tenha sido descontada pela outra.

Na segunda função, o Mg destaca-se das demais variáveis

Tabela 1 - Poder de discriminação das funções discriminantes para os oito grupos de solo

\begin{tabular}{|c|c|c|c|c|c|c|c|c|c|}
\hline $\begin{array}{c}\text { FUNÇÃO } \\
\text { DISCRIMINANTE }\end{array}$ & $\begin{array}{l}\text { AUTOR } \\
\text { VALOR }\end{array}$ & $\begin{array}{l}\text { PORCENTAGEM } \\
\text { RELATIVA }\end{array}$ & $\begin{array}{c}\text { CORRELAÇÃO } \\
\text { CANÔNICA }\end{array}$ & & $\begin{array}{l}\text { FUNÇÕES } \\
\text { DERIVADAS }\end{array}$ & $\begin{array}{l}\text { LAMBDA } \\
\text { DE WILK }\end{array}$ & CHI-QUADRADO & GL & $\begin{array}{l}\text { SIGNIFI- } \\
\text { CÂNCIA }\end{array}$ \\
\hline 1 & 5,89787 & 46,16 & 0,925 & : & 0 & 0.0034 & 903,317 & 70 & 0,000 \\
\hline 2 & 3,34024 & 26,14 & 0,877 & : & 1 & 0,0235 & 596,254 & 54 & 0,000 \\
\hline 3 & 2,04606 & 16,01 & 0,820 & : & 2 & 0,1021 & 362,854 & 40 & 0,000 \\
\hline 4 & 0,91219 & 7,14 & 0,691 & : & 3 & 0,3109 & 185,752 & 28 & 0,000 \\
\hline 5 & 0,29891 & 2,34 & 0,480 & : & 4 & 0,5945 & 82,681 & 18 & 0,000 \\
\hline 6 & 0,22811 & 1,79 & 0,431 & : & 5 & 0,7722 & 41,098 & 10 & 0,000 \\
\hline 7 & 0,05443 & 0,43 & 0,227 & : & 6 & 0,9484 & 8,427 & 4 & 0,077 \\
\hline
\end{tabular}


Tabela 2 - Coeficientes padronizados das funções discriminantes

\begin{tabular}{|c|c|c|c|c|c|c|c|}
\hline VARIÁVEIS & $\begin{array}{c}\text { FUNÇÃo } \\
1\end{array}$ & $\begin{array}{c}\text { FUNÇÃO } \\
\mathbf{2}\end{array}$ & $\begin{array}{c}\text { FUNÇÃo } \\
3\end{array}$ & \begin{tabular}{|c|} 
FUNÇÃO \\
4
\end{tabular} & \begin{tabular}{|c|} 
FUNÇÃo \\
5
\end{tabular} & $\begin{array}{c}\text { FUNÇÃO } \\
6\end{array}$ & $\begin{array}{c}\text { FUNÇĀO } \\
7\end{array}$ \\
\hline Al. & 0,05323 & $-0,19337$ & 0,36129 & 0,01542 & $-0,40806$ & $-1,27827$ & 0.15653 \\
\hline $\mathrm{Fe}$ & $-0,28196$ & $-0,30167$ & $-0,25854$ & 0,76563 & $-0,77203$ & $-0,53282$ & $-0,35873$ \\
\hline $\mathrm{Mg}$ & 0,23756 & $-0,82175$ & $-0,50455$ & $-0,54903$ & $-0,25128$ & $-0,46184$ & $-0,33011$ \\
\hline $\mathrm{Mn}$ & $-0,16028$ & $-0,36931$ & $-0,14543$ & 0,79012 & $-0,42087$ & $-0,10500$ & $-0,30895$ \\
\hline $\mathrm{Ti}$ & 0,04435 & $-0,01066$ & $-0,00463$ & $-0,14671$ & $-0,38084$ & 0,11786 & 0,71764 \\
\hline Co & $-0,20934$ & $-0,12149$ & 0,19225 & 0,11037 & 0,01622 & $-0,30307$ & 0,81641 \\
\hline $\mathrm{Ni}$ & 0,22010 & 0,08147 & 0,25749 & $-0,03563$ & 0,74603 & 1,55227 & 0,02276 \\
\hline $\mathrm{v}$ & 0,20097 & $-0,08770$ & 0,41922 & $-0,20469$ & 0,12831 & $-0,04852$ & $-0,33394$ \\
\hline $\mathrm{Cu}$ & $-0,30663$ & 0,01021 & $-0,07550$ & $-0,32144$ & 0,55695 & $-0,27669$ & 0,59035 \\
\hline $\mathrm{Zn}$ & $-0,14717$ & $\begin{array}{r}-0,18407 \\
-0\end{array}$ & 0,01792 & 0,25204 & 0,50906 & $-0,38302$ & $-0,51279$ \\
\hline
\end{tabular}

por seu alto coeficiente de discriminação. Outras variáveis que se destacam nessa função, porém em plano secundário, são o $\mathrm{Mn}$ e o $\mathrm{Fe}$. Esses três elementos contribuem negativamente para a função (Tab. 2), logo ela mede a ausência deles nos elementos amostrais. Essa função acentua a diferença existente entre os grupos 5 e 7 devido ao mais alto teor de manganês no Grupo 7 (Fig. 4 e Tab. 3). A grande influência do $\mathrm{Mg}$ e secundariamente a do $\mathrm{Mn}$ nessa função são decisivas para a discriminação dos grupos 2, 3 e 4 entre si (Fig. 4). Observa-se claramente um aumento na concentração desses elementos no sentido do Grupo 2 para o Grupo 4 (Tab. 3).

$\mathrm{O} \mathrm{Mg}$ permanece como a variável mais significativa na terceira função, seguida mais de perto por $\mathrm{V}$ e $\mathrm{Al}$. $\mathrm{O}$ primeiro elemento contribui negativamente enquanto os dois últimos dão uma contribuição positiva na função. Basicamente, essa função mede a ausência de $\mathrm{Mg}$ e a presença de $\mathrm{Al}$ e V nos elementos amostrais. Como conseqüẽncia da influência significativa de $\mathrm{V}$ e $\mathrm{Al}$ nessa função, o Grupo 6, finalmente, é individualizado devido a seu mais baixo teor desses dois elementos (Fig. 4 e Tab. 3).

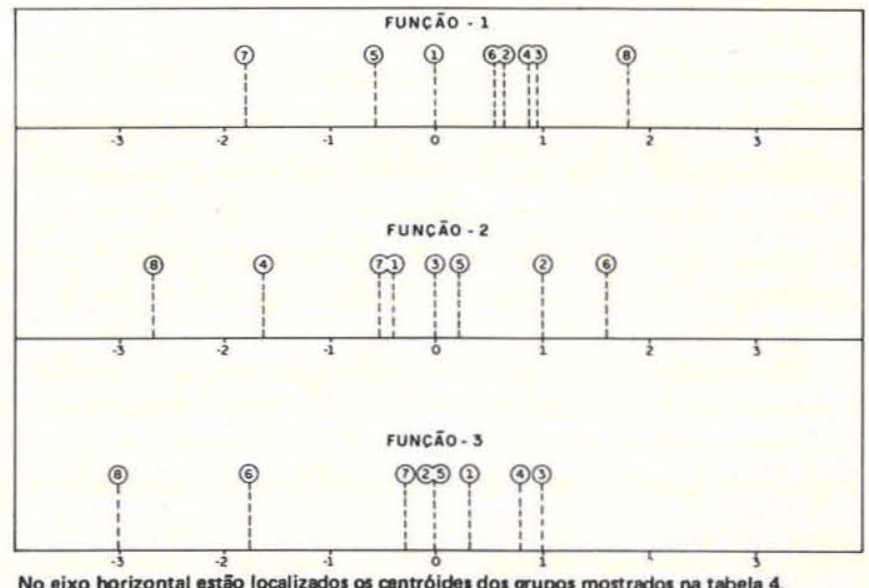

No eixo horizontal estâo localizados os centróides dos grupos mostrados na tabela 4. Os números dentro dos círculos representam os grupos de solos.

Figura 4 - Quadro mostrando a posição da centróide dos oito grupos de solo com relação as três primeiras funções discriminantes

A média da composição química dos elementos amostrais classificados no Grupo 1 é muito semelhante à média total da composição química (Tab. 3). Talvez por isso não exista um elemento ou elementos químicos que caracterizam especificamente a discriminação desse grupo dos demais. Acredita-se que sua discriminação tenha sido fruto de somatória da contribuição das variáveis mais significativas em cada uma das funções consideradas.

Nessas três funções analisadas, apenas $\mathrm{Zn}$ e Ti não contribuem significativamente na discriminação dos grupos de solos.

Tabela 3 - Média $(\bar{X})$ e desvio padrão (s) para cada grupo de solo e para o total dos elementos amostrais

\begin{tabular}{|c|c|c|c|c|c|c|c|c|c|c|}
\hline $\begin{array}{c}\text { N.o de } \\
\text { amostras }\end{array}$ & & 41 & 27 & 19 & 09 & 35 & 10 & 23 & 06 & 169 \\
\hline Variáveis & & Grupo 1 & Grupo 2 & Grupo 3 & Grupo 4 & Grupo 5 & Grupo 6 & Grupo 7 & Grupo 8 & Total \\
\hline $\mathrm{Al}$ & $\begin{array}{c}\bar{X} \\
s\end{array}$ & $\begin{array}{r}11,8049 \\
1,6371\end{array}$ & $\begin{array}{r}11,8644 \\
0,8619\end{array}$ & $\begin{array}{r}13,4858 \\
1,2400\end{array}$ & $\begin{array}{r}13,2333 \\
1,0713\end{array}$ & $\begin{array}{r}10,1429 \\
1,1732\end{array}$ & $\begin{array}{l}8,5250 \\
1,9785\end{array}$ & $\begin{array}{l}9,3374 \\
0,9839\end{array}$ & $\begin{array}{l}9,1020 \\
0,6511\end{array}$ & $\begin{array}{r}11,1254 \\
1,9569\end{array}$ \\
\hline $\mathrm{Fe}$ & $\begin{array}{c}\bar{X} \\
s\end{array}$ & $\begin{array}{r}14,9202 \\
2,1149\end{array}$ & $\begin{array}{r}12,6333 \\
2,7206\end{array}$ & $\begin{array}{r}13,5284 \\
1,3275\end{array}$ & $\begin{array}{r}13,8789 \\
0,7558\end{array}$ & $\begin{array}{r}18,7123 \\
2,3299\end{array}$ & $\begin{array}{l}9,3010 \\
2,4594\end{array}$ & $\begin{array}{r}19,8996 \\
1,4564\end{array}$ & $\begin{array}{l}8,9560 \\
1,2436\end{array}$ & $\begin{array}{r}15,2970 \\
3,8035\end{array}$ \\
\hline $\mathrm{Mg}$ & $\begin{array}{l}\overline{\bar{X}} \\
\mathrm{~s}\end{array}$ & $\begin{array}{l}0,1068 \\
0,0685\end{array}$ & $\begin{array}{l}0,0644 \\
0,0204\end{array}$ & $\begin{array}{l}0,1174 \\
0,0515\end{array}$ & $\begin{array}{l}0,2956 \\
0,1083\end{array}$ & $\begin{array}{l}0,0500 \\
0,0369\end{array}$ & $\begin{array}{l}0,0810 \\
0,0285\end{array}$ & $\begin{array}{l}0,0509 \\
0,0281\end{array}$ & $\begin{array}{l}0,6340 \\
0,2411\end{array}$ & $\begin{array}{l}0,1060 \\
0,1243\end{array}$ \\
\hline $\mathrm{Mn}$ & $\begin{array}{c}\bar{X} \\
s\end{array}$ & $\begin{array}{l}0,3632 \\
0,1123\end{array}$ & $\begin{array}{l}0,0622 \\
0,0526\end{array}$ & $\begin{array}{l}0,1895 \\
0,0694\end{array}$ & $\begin{array}{l}0,2944 \\
0,0430\end{array}$ & $\begin{array}{l}0,1937 \\
0,1051\end{array}$ & $\begin{array}{l}0,0660 \\
0,0717\end{array}$ & $\begin{array}{l}0,3400 \\
0,1195\end{array}$ & $\begin{array}{l}0,2120 \\
0,1207\end{array}$ & $\begin{array}{l}0,2316 \\
0,1468\end{array}$ \\
\hline $\mathrm{Ti}$ & $\begin{array}{c}\bar{X} \\
s\end{array}$ & $\begin{array}{l}0,6034 \\
0,1564\end{array}$ & $\begin{array}{l}0,6233 \\
0,1305\end{array}$ & $\begin{array}{l}0,5426 \\
0,1325\end{array}$ & $\begin{array}{l}0,6489 \\
0,1191\end{array}$ & $\begin{array}{l}0,6069 \\
0,2193\end{array}$ & $\begin{array}{l}0,5540 \\
0,0893\end{array}$ & $\begin{array}{l}0,4743 \\
0,1113\end{array}$ & $\begin{array}{l}0,9320 \\
0,1994\end{array}$ & $\begin{array}{l}0,5921 \\
0,1728\end{array}$ \\
\hline Co & $\begin{array}{c}\bar{X} \\
s\end{array}$ & $\begin{array}{l}83,9268 \\
18,9702\end{array}$ & $\begin{array}{l}40,2593 \\
11,9473\end{array}$ & $\begin{array}{l}62,6316 \\
16,5402\end{array}$ & $\begin{array}{r}103,0000 \\
18,4187\end{array}$ & $\begin{array}{l}57,0857 \\
17,6275\end{array}$ & $\begin{array}{l}35,0000 \\
14,2595\end{array}$ & $\begin{array}{l}91,9130 \\
33,2906\end{array}$ & $\begin{array}{l}59,6000 \\
26,4064\end{array}$ & $\begin{array}{l}67,4852 \\
28,5128\end{array}$ \\
\hline $\mathrm{Ni}$ & $\begin{array}{c}\bar{X} \\
s\end{array}$ & $\begin{array}{l}78,8049 \\
23,0372\end{array}$ & $\begin{array}{l}53,1852 \\
12,3912\end{array}$ & $\begin{array}{l}92,8842 \\
23,4640\end{array}$ & $\begin{array}{r}129,3333 \\
19,0000\end{array}$ & $\begin{array}{l}50,7143 \\
12,3564\end{array}$ & $\begin{array}{l}44,3000 \\
10,1110\end{array}$ & $\begin{array}{l}46,7826 \\
14,4221\end{array}$ & $\begin{array}{l}75,6000 \\
47,5268\end{array}$ & $\begin{array}{l}66,6509 \\
28,8981\end{array}$ \\
\hline V & $\begin{array}{c}\bar{X} \\
s\end{array}$ & $\begin{array}{r}269,1120 \\
39,8831\end{array}$ & $\begin{array}{r}254,4444 \\
43,0745\end{array}$ & $\begin{array}{r}328,9474 \\
41,8358\end{array}$ & $\begin{array}{r}344,1111 \\
33,8580\end{array}$ & $\begin{array}{r}258,6857 \\
44,4402\end{array}$ & $\begin{array}{r}135,2000 \\
57,2922\end{array}$ & $\begin{array}{r}204,2609 \\
44,6494\end{array}$ & $\begin{array}{r}206,6000 \\
48,5984\end{array}$ & $\begin{array}{r}256,7337 \\
64,5796\end{array}$ \\
\hline $\mathrm{Cu}$ & $\begin{array}{c}\bar{X} \\
s\end{array}$ & $\begin{array}{l}421,0000 \\
168,7125\end{array}$ & $\begin{array}{l}444,7778 \\
160,6863\end{array}$ & $\begin{array}{r}374,4737 \\
84,5822\end{array}$ & $\begin{array}{l}587,6667 \\
247,4621\end{array}$ & $\begin{array}{l}741,1143 \\
196,5523\end{array}$ & $\begin{array}{l}266,7000 \\
135,7678\end{array}$ & $\begin{array}{l}975,3478 \\
202,9540\end{array}$ & $\begin{array}{r}236,4000 \\
87,9323\end{array}$ & $\begin{array}{l}555,5917 \\
279,6740\end{array}$ \\
\hline $\mathrm{Zn}$ & $\begin{array}{c}\bar{X} \\
s\end{array}$ & $\begin{array}{r}114,7805 \\
47,8777\end{array}$ & $\begin{array}{l}46,0370 \\
23,8335\end{array}$ & $\begin{array}{l}88,0000 \\
33,6667\end{array}$ & $\begin{array}{r}162,8889 \\
54,4322\end{array}$ & $\begin{array}{r}135,0571 \\
79,5938\end{array}$ & $\begin{array}{l}68,1000 \\
37,9047\end{array}$ & $\begin{array}{l}346,9565 \\
274,4995\end{array}$ & $\begin{array}{r}158,0000 \\
56,0089\end{array}$ & $\begin{array}{l}137,6627 \\
142,4290\end{array}$ \\
\hline
\end{tabular}


Tabela 4 - Centróides dos escores discriminantes para os oito grupos de solo

\begin{tabular}{|c|c|c|c|c|c|c|c|}
\hline GRUPO & $\begin{array}{c}\text { FUNÇÃO } \\
1\end{array}$ & $\begin{array}{c}\text { FUNÇÃO } \\
2\end{array}$ & $\underset{3}{\text { FUNÇÃo }}$ & $\begin{array}{c}\text { FUNÇÃo } \\
4\end{array}$ & $\begin{array}{c}\text { FUNÇĀO } \\
5\end{array}$ & $\underset{6}{\text { FUNÇÃO }}$ & $\begin{array}{c}\text { FUNÇĀo } \\
7\end{array}$ \\
\hline Grupo 1 & 0,08894 & $-0,40233$ & 0,29880 & 0,88869 & $-0,47101$ & 0,07499 & 0,07224 \\
\hline Grupo 2 & & & $-0,00914$ & $-0,34037$ & $-0,02864$ & $-0,63155$ & 0,22424 \\
\hline Grupo 3 & 0,95890 & $-0,00493$ & 1,02304 & $-0,05703$ & 0,34819 & $-0,12643$ & $-0,48701$ \\
\hline Grupo 4 & 0,89811 & $-1,63445$ & 0,81921 & $-0,48754$ & 1,12582 & 0,53312 & 0,49374 \\
\hline Grupo 5 & 0,58142 & 0,29754 & 0,06522 & $-0,89347$ & $-0,35238$ & 0,44330 & $-0,03059$ \\
\hline Grupo 6 & 0,57566 & 1,63494 & $-1,75914$ & 0,97507 & 0,70758 & 0,75731 & $-0,06481$ \\
\hline Grupo 7 & $-1,81415$ & 0,43399 & 0,33771 & 0,18761 & 0,47963 & 0,40940 & $-0,06042$ \\
\hline Grupo 8 & 1,83179 & $-2,67120$ & $-3,14778$ & $-0,91379$ & $-0,48747$ & $-0,41824$ & $-0,21965$ \\
\hline
\end{tabular}

Tabela 5 - Previsão dos resultados de classificação das amostras para os grupos de solo, segundo a análise discriminante

\begin{tabular}{|c|c|c|c|c|c|c|c|c|c|}
\hline \multirow{2}{*}{$\begin{array}{c}\text { GRUPO } \\
\text { VERDADEIRO }\end{array}$} & \multirow{2}{*}{$\begin{array}{c}\text { No DE ELEMENTOS } \\
\text { AMOSTRAIS }\end{array}$} & \multicolumn{8}{|c|}{ PREVISÃO DOS GRUPOS (\%) } \\
\hline & & GP 1 & GP 2 & GP 3 & GP 4 & GP 5 & GP 6 & GP 7 & GP 8 \\
\hline GRUPO I & 41 & $\begin{array}{l}35 \\
85,4\end{array}$ & $\begin{array}{l}1 \\
2,4\end{array}$ & $\begin{array}{l}3 \\
4,9\end{array}$ & $\begin{array}{l}0 \\
0,0\end{array}$ & $\begin{array}{l}2 \\
4,9\end{array}$ & $\begin{array}{l}0 \\
0,0\end{array}$ & $\begin{array}{l}0 \\
0,0\end{array}$ & $\begin{array}{l}0 \\
0,0\end{array}$ \\
\hline GRUPO 2 & 27 & $\begin{array}{l}0 \\
0,0\end{array}$ & $\begin{array}{l}26 \\
96,3\end{array}$ & $\begin{array}{l}0 \\
0,0\end{array}$ & $\begin{array}{l}0 \\
0,0\end{array}$ & $\begin{array}{l}1 \\
3,7\end{array}$ & $\begin{array}{l}0 \\
0,0\end{array}$ & $\begin{array}{l}0 \\
0,0\end{array}$ & $\begin{array}{l}0 \\
0,0\end{array}$ \\
\hline GRUPO 3 & 19 & $\begin{array}{l}0 \\
0,0\end{array}$ & $\stackrel{2}{10,5}$ & $\begin{array}{l}17 \\
89,5\end{array}$ & $\begin{array}{l}0 \\
0,0\end{array}$ & $\begin{array}{l}0 \\
0,0\end{array}$ & $\begin{array}{l}0 \\
0,0\end{array}$ & $\begin{array}{l}0 \\
0,0\end{array}$ & $\begin{array}{l}0 \\
0,0\end{array}$ \\
\hline GRUPO 4 & 09 & $\begin{array}{l}0 \\
0,0\end{array}$ & $\begin{array}{l}0 \\
0,0\end{array}$ & $\begin{array}{c}1 \\
11,1\end{array}$ & $\begin{array}{c}8 \\
88,9\end{array}$ & $\begin{array}{l}0 \\
0,0\end{array}$ & $\begin{array}{l}0 \\
0,0\end{array}$ & $\begin{array}{l}0 \\
0,0\end{array}$ & $\begin{array}{l}0 \\
0,0\end{array}$ \\
\hline GRUPO 5 & 35 & ${ }_{2,9}^{1}$ & $\begin{array}{l}2 \\
5,7\end{array}$ & $\begin{array}{l}0 \\
0,0\end{array}$ & $\begin{array}{l}0 \\
0,0\end{array}$ & $\begin{array}{l}32 \\
91,4\end{array}$ & $\begin{array}{l}0 \\
0,0\end{array}$ & $\begin{array}{l}0 \\
0,0\end{array}$ & $\begin{array}{l}0 \\
0,0\end{array}$ \\
\hline GRUPO 6 & 10 & $\begin{array}{l}0 \\
0,0\end{array}$ & $\begin{array}{l}0 \\
0,0\end{array}$ & $\begin{array}{l}0 \\
0,0\end{array}$ & $\begin{array}{l}0 \\
0,0\end{array}$ & $\begin{array}{l}0 \\
0,0\end{array}$ & $\begin{array}{c}10 \\
100,0\end{array}$ & $\begin{array}{l}0 \\
0,0\end{array}$ & $\begin{array}{l}0 \\
0,0\end{array}$ \\
\hline GRUPO 7 & 23 & $\begin{array}{l}0 \\
0,0\end{array}$ & $\begin{array}{l}0 \\
0,0\end{array}$ & $\begin{array}{l}0 \\
0,0\end{array}$ & $\begin{array}{l}0 \\
0,0\end{array}$ & $\begin{array}{l}2 \\
8,7\end{array}$ & $\begin{array}{l}0 \\
0,0\end{array}$ & $\begin{array}{l}21 \\
91,3\end{array}$ & $\begin{array}{l}0 \\
0,0\end{array}$ \\
\hline GRUPO 8 & 05 & $\begin{array}{l}0 \\
0,0\end{array}$ & $\begin{array}{l}0 \\
0,0\end{array}$ & $\begin{array}{l}0 \\
0,0\end{array}$ & $\begin{array}{l}0 \\
0,0\end{array}$ & $\begin{array}{l}0 \\
0,0\end{array}$ & $\begin{array}{l}0 \\
0,0\end{array}$ & $\begin{array}{l}0 \\
0,0\end{array}$ & $\begin{array}{c}0 \\
100,0\end{array}$ \\
\hline
\end{tabular}

Como observação relevante, decorrente da aplicação das análises de agrupamentos e discriminante nos dados geoquímicos de solo ao Alvo 2 - Corpo 4, destaca-se a alta concentração de $\mathrm{Cu}$ nos elementos amostrais classificados nos grupos 5 e 7, e a alta concentração de $\mathrm{Zn}$ naqueles classificados no Grupo 7. Esses dados evidenciam a presença de uma zona geoquimicamente anômala para $\mathrm{Cu}$ e $\mathrm{Zn}$ associada à faixa central de anfibólio xistos.

CONCLUSÓES Com base nas variáveis previamente selecionadas, foram identificadas pela análise de agrupamentos oito grupos de solos geoquimicamente homogêneos e estreitamente relacionados com as rochas subjacentes. A análise discriminante mostra que esta classificação pode ser aceita estatisticamente. Revela ainda que das variáveis selecionadas apenas $\mathrm{Zn}$ e Ti não exercem um papel significativo no processo de discriminação dos grupos de solo.

Os resultados obtidos na aplicação conjunta da análise de agrupamentos e discriminante demonstram que o tratamento estatístico multivariante em dados geoquímicos de solo constitui uma importante ferramenta no auxílio do mapeamento geológico em áreas tropicais. As técnicas estatísticas utilizadas permitem também determinar, em linhas gerais, características composicionais de cada grupo de solo identificado, tornando, desse modo, evidente o estreito relacionamento existente entre os altos teores de $\mathrm{Cu}$ e $\mathrm{Zn}$ no solo e anfibólio xistos. Isso vem mostrar também que essas técnicas podem ser empregadas com sucesso na seleção de alvos para a prospecção.

Agradecimentos Esse trabalho é parte integrante da dissertação apresentada pelo Autor, como requisito parcial à obtenção do grau de Mestre em Ciências na área de Geoquímica, ao Curso de Pós-Graduação em Ciências Geofísicas e Geológicas da Universidade Federal do Pará. A todas as pessoas que colaboraram direta ou indiretamente nessa iniciativa, o Autor agradece, mas não poderia deixar de citar nominalmente o Prof. José Francisco da Fonseca Ramos, que o orientou na execução dos trabalhos.

O Autor expressa também sinceros agradecimentos ao Centro de Geociências da UFPa, que proporcionou a oportunidade para o desenvolvimento desse trabalho. $\grave{A}$ Docegeo, que concordou com a realização do trabalho em área requerida para suas pesquisas e concedeu tanto o apoio logístico como permitiu a consulta dos relatórios geológicos existentes sobre o Alvo 2 - Corpo 4. Os agradecimentos são extensivos também à Finep e ao $\mathrm{CNPq}$ pelo auxílio financeiro, fundamental para a concretização desse trabalho.

\section{REFERENCIAS BIBLIOGRAFICAS}

BOCK, R. - 1972 - Aufslchussmethoden der anorganischen und organischen Chemie. Weinhein/Bergsts, Verlag Chemie, $232 \mathrm{p}$.

BERNADELLI, A.L.; MEIRELES, E.M.; TEIXEIRA, J.T.; SAUERESSIG, R.; ASSAD, R.; BEISIEGEL, V.R.; HIRATA, W.K. - 1982 - Província mineral de Carajás-Pará: depósito de ferro, manganês, cobre, ouro, níquel e bauxita. In: SIMP. GEOL. AMAZ., 19., Belém, 1982. Anais... Belém. SBG/No. Anexo, $104 \mathrm{p}$.

DAVIS, J.C. - 1973 - Statistic and data analysis on Geology. New York, John Wiley \& Sons. 550 p.

GUIMARĀES, I.G. \& AMARAL, M.A.M. - 1980 - Relatório de Estudos no LXIX Projeto Cobre Carajás (PE-15). Belo Horizonte, Companhia Vale do Rio Doce. 39 p.

GUIMARÃES, I.G. \& TOWNEND, R. - 1979 - Amostras referentes à viagem da Dra. Ignês Gomes Guimarães e Dr. Roger Townend. Relatório de Discriminação petrográfica. Projeto Cobre Carajás (PE-15). Belo Horizonte, Companhia Vale do Rio Doce. 12 p.

HIRATA, W.K.; RIGON, J.C.; KADEKARU, K.; CORDEIRO, A.A.C.; MEIRELES, E.M. - 1982 - Geologia Regional da Província Mineral de Carajás. In: SIMP. GEOL. AMAZ., 1, Belém, 1982. Atas... Belém, SBG, v. 1, p. 100-110.

KLECKA, W.S. - 1975 - Discriminant analysis. In: NIE, N.H.; HULL, C.H.; JENKING, J.G.; STREINBRENNER, K.
Statistical package for the social Sciences. New York, McGraw-Hill, p. 434-467.

KOCH Jr., G.S. \& LINK, R.F. - 1971 - Statistical analysis of geological data. New York, John Wiley \& Sons. V. 2.

LANDIM, P.M.B. - 1976 - Aplicação da análise de agrupamentos (cluster analysis) em Bioestratigrafia. In: CONG. BRAS. GEOL., 29, Ouro Preto, 1976. Anais... Ouro Preto, SBG, v. 2, p. 81-88.

MOURA, C.A.V. - 1982 - Tratamento estatístico de dados geoquimicos e a sua aplicação ao mapeamento geológico e definição de anomalias geoquímicas no Alvo 2 - Corpo 4 - Província Mineral de Carajás. (Dissertação de Mestrado, Núcleo de Ciências Geofísicas e Geológicas, Universidade Federal do Pará). 109 p.

NIE, N.H.; HULL, C.H.; JENKINS, J.G.; STEINBRENNER, K. 1975 - Statistical package for the social sciences. New York. McGraw-Hill. 675 p.

PARKS, J.M. - 1966 - Cluster analysis applied to multivariante geologic problems. J. Geology, part. 2, 74 (5) : 703-705.

ROY, A. - 1981 - Application of cluster analysis in the interpretation of geochemical data from the Sergipalli lead-zinc area, Sundergerh. Orissa (India). J. Geochem. Explor. 14 (2/3) : 245-264.

SILVA, W.R.L. - 1980 - Dispersão geoquímica dos elementos Si, 
$\mathrm{Al}, \mathrm{Fe}, \mathrm{Mn}, \mathrm{Na}, \mathrm{K}, \mathrm{Cu}$ e $\mathrm{Zn}$ nos solos de sua aplicação na caracterização de áreas geoquimicamente homogêneas. (Tese de mestrado, Núcleo de Ciências Geofísicas e Geológicas, Universidade Federal do Pará). 115 p.

SOBREIRO NETO, A.P. \& CAMPOS, H.C.N.S. - 1980 - Análise de agrupamentos - Um método auxiliar na caracterização de aquíferos. In: CONG. BRAS. GEOL. 31, Camboriú, 1980. Anais... Camboriú, SBG, v. 2, p. 1041-1055.

MANUSCRITO

Recebido em 12 de agosto de 1985 Revisão aceita em 27 de janeiro de 1986

\section{Anexo 1 - Resultados analiticos.}

\begin{tabular}{|c|c|c|c|c|c|c|c|c|c|c|}
\hline & & & & & & & & (ppm) & & \\
\hline & 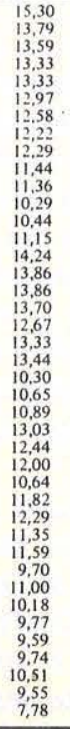 & 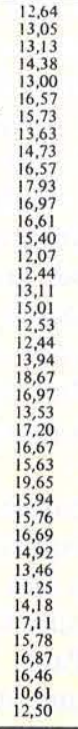 & 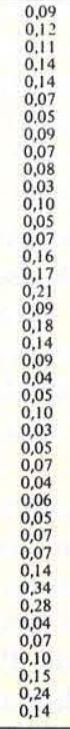 & 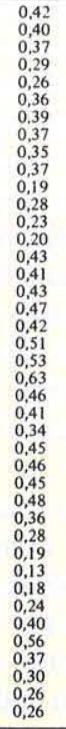 & 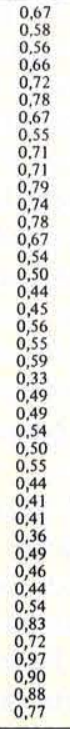 & $\begin{array}{l}0 \\
0 \\
0 \\
0 \\
0 \\
0 \\
0 \\
0 \\
0 \\
0 \\
0 \\
0 \\
0 \\
0 \\
0 \\
0 \\
0 \\
0 \\
0 \\
0 \\
b \\
b \\
b \\
b \\
b \\
b\end{array}$ & 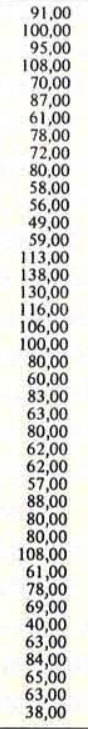 & 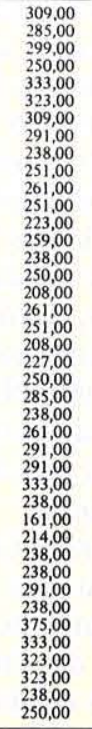 & 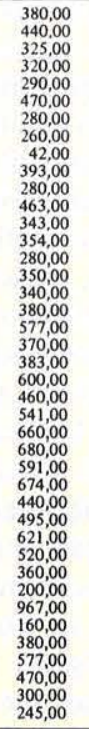 & 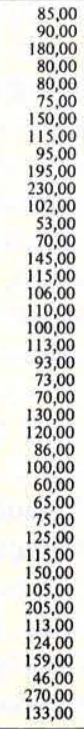 \\
\hline PO 02 & (") & ${ }^{F}$ & $\begin{array}{c}\mathrm{Ms}_{\mathrm{s}} \\
\end{array}$ & $(9$ & $\begin{array}{l}\mathrm{Ti} \\
(\%) \\
\end{array}$ & & & (ppm) & & $\begin{array}{l}2 \mathrm{n} \\
\text { pem) }\end{array}$ \\
\hline & 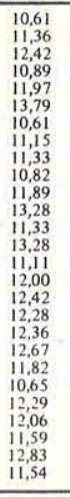 & 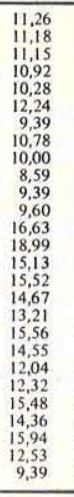 & 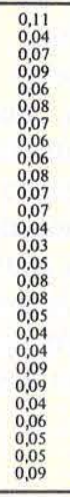 & $\begin{array}{lll} & 0,21 \\
0,04 \\
0,03\end{array}$ & 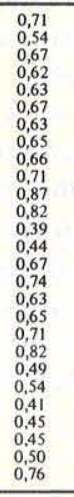 & $\begin{array}{l}5,1,0,00 \\
5,0,00\end{array}$ & 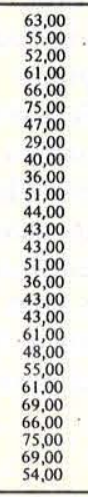 & 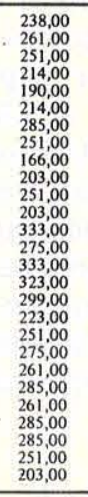 & & $\begin{array}{r}67,0,0 \\
38,0 \\
47,0\end{array}$ \\
\hline 003 & 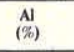 & 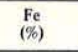 & $\begin{array}{l}M_{\text {ss }} \\
(\%)\end{array}$ & $\frac{M}{M}$ & $\underset{(\%)}{\mathrm{F}_{(\%)}}$ & & & & & $\begin{array}{l}\mathrm{Zn}_{\mathrm{n}} \\
\mathrm{ppm})\end{array}$ \\
\hline & & & 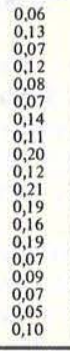 & $\begin{array}{l}\text {, } \\
0, \\
0, \\
0, \\
0, \\
0,\end{array}$ & & & 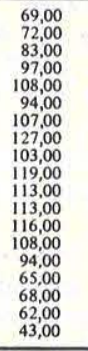 & & & $\begin{array}{l}140,0,0 \\
1720 \\
95,0 \\
45,0 \\
10,0\end{array}$ \\
\hline & & & & (y) & & & & & & $\begin{array}{l}\mathrm{zn} \\
\mathrm{ppm})\end{array}$ \\
\hline & & & & & & & & & & \\
\hline
\end{tabular}

\begin{tabular}{|c|c|c|c|c|c|c|c|c|c|c|}
\hline 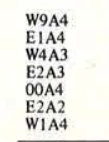 & $\begin{array}{l}4,85 \\
4,22 \\
11,82 \\
3,44 \\
3,28 \\
2,67 \\
1,82\end{array}$ & $\begin{array}{l}13,70 \\
13,703 \\
13,6.62 \\
13,94 \\
14,55 \\
14,44 \\
15,20 \\
15,20\end{array}$ & $\begin{array}{l}0.14 \\
0.27 \\
0.222 \\
0.25 \\
0.44 \\
0.51 \\
0,26\end{array}$ & $\begin{array}{l}0,39 \\
0,29 \\
0,33 \\
0,29 \\
0,25 \\
0,29 \\
0,28\end{array}$ & $\begin{array}{l}0.54 \\
0.57 \\
0,80 \\
0.86 \\
0.52 \\
0.66 \\
0,67\end{array}$ & $\begin{array}{l}102,00 \\
105,00 \\
105,00 \\
85,00 \\
115,00 \\
89,00 \\
144,00\end{array}$ & $\begin{array}{l}127,00 \\
127,00 \\
136,00 \\
10,900 \\
158,00 \\
153,00 \\
125,00\end{array}$ & $\begin{array}{l}357.00 \\
416,00 \\
309,00 \\
323,00 \\
370,00 \\
347,00 \\
333,00\end{array}$ & $\begin{array}{r}420,00 \\
460,00 \\
340,00 \\
441,00 \\
561100 \\
645,00 \\
6151,00\end{array}$ & $\begin{array}{r}155,00 \\
217,00 \\
250,00 \\
92.00 \\
144,00 \\
203,00 \\
155,00\end{array}$ \\
\hline GRUPO 05 & Al & $\begin{array}{c}\mathrm{Fe} \\
(\%)\end{array}$ & $\begin{array}{l}\text { Ms } \\
(\%)\end{array}$ & $\begin{array}{l}\mathrm{Mn} \\
(\%)\end{array}$ & $\begin{array}{c}\mathrm{Ti} \\
(\%)\end{array}$ & 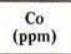 & $\underset{(\mathrm{ppm})}{\mathrm{Ni}}$ & $\underset{(p p m)}{v}$ & $\underset{(\mathrm{ppm})}{\mathrm{Cu}}$ & $\begin{array}{c}\mathrm{zn}_{(\mathrm{n}} \\
\text { (p) }\end{array}$ \\
\hline 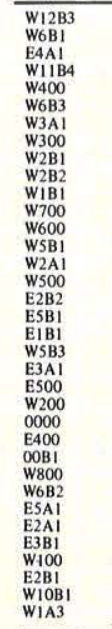 & 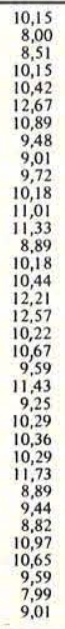 & 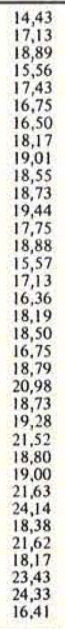 & 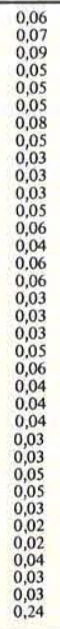 & 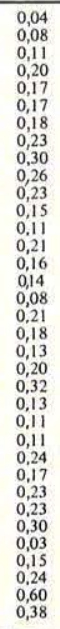 & 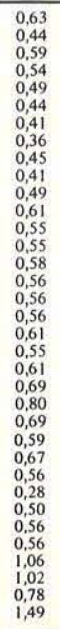 & 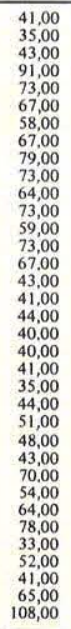 & 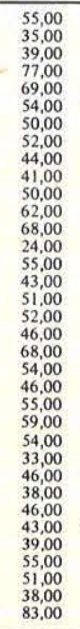 & 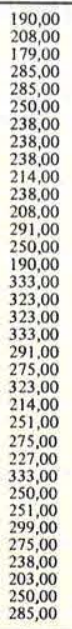 & 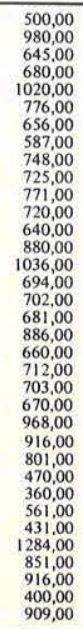 & 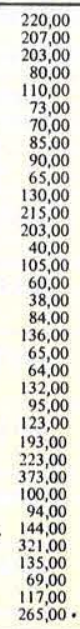 \\
\hline GRUPO 06 & $\begin{array}{l}\mathrm{A} / \\
(\%)\end{array}$ & $\begin{array}{l}\mathrm{Fe} \\
(\%)\end{array}$ & $\begin{array}{l}\text { Ms } \\
(\%)\end{array}$ & $\begin{array}{l}\mathrm{Mn} \\
(\%)\end{array}$ & (\%) & (ppm & (ppm) & (ppm) & $\underset{(\mathrm{ppm})}{\mathrm{Cu}}$ & $\underset{(\mathrm{ppm})}{\mathrm{Zn}}$ \\
\hline 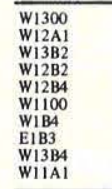 & $\begin{array}{r}6,21 \\
5,45 \\
9,85 \\
9,70 \\
10,00 \\
7,73 \\
10,65 \\
10,82 \\
8,48 \\
6,36\end{array}$ & $\begin{array}{r}4,43 \\
13,70 \\
11,34 \\
9,39 \\
9.39 \\
9,90 \\
9,68 \\
10,38 \\
7,36 \\
7,361 \\
8,01\end{array}$ & $\begin{array}{l}0,07 \\
0,09 \\
0,05 \\
0,08 \\
0,07 \\
0,08 \\
0,06 \\
0,06 \\
0,10 \\
0,15\end{array}$ & $\begin{array}{l}0.04 \\
0,02 \\
0,15 \\
0,12 \\
0,03 \\
0,22 \\
0,02 \\
0,02 \\
0,02 \\
0,02\end{array}$ & $\begin{array}{l}0,58 \\
0,58 \\
0.54 \\
0.51 \\
0.71 \\
0.63 \\
0.58 \\
0,58 \\
0.50 \\
0.42 \\
0,42 \\
0,42\end{array}$ & $\begin{array}{l}29,00 \\
11,00 \\
55,00 \\
47,00 \\
29,00 \\
55,00 \\
20,00 \\
37,00 \\
32,00 \\
35,00\end{array}$ & $\begin{array}{l}30,00 \\
27,00 \\
55,00 \\
52,00 \\
44,00 \\
41,00 \\
41,00 \\
57,00 \\
44,00 \\
52,00\end{array}$ & 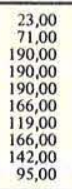 & $\begin{array}{l}100,00 \\
100,00 \\
344,00 \\
220,00 \\
200,00 \\
200,00 \\
368,00 \\
519,00 \\
220,00 \\
400,00\end{array}$ & $\begin{array}{r}37,00 \\
30,00 \\
125,00 \\
10,000 \\
80,00 \\
115,00 \\
42,00 \\
32,00 \\
30,00 \\
90,00\end{array}$ \\
\hline RUPO 07 & $\begin{array}{l}\mathrm{A} \\
(\%)\end{array}$ & $\begin{array}{l}\mathrm{Fe} \\
\text { (\%) }\end{array}$ & $\begin{array}{l}\text { Ms } \\
(\%)\end{array}$ & $\begin{array}{l}\mathrm{Mn} \\
(\%)\end{array}$ & (\%) & (ppm) & $\begin{array}{c}\mathrm{Ni} \\
(\mathrm{ppm})\end{array}$ & $\underset{(p p m)}{v}$ & (ppm) & $\begin{array}{c}\mathrm{Zn}_{(\mathrm{ppm})} \\
\text { (2) }\end{array}$ \\
\hline & $\begin{array}{c}10,30 \\
9,11 \\
9,23 \\
9,70 \\
8,05 \\
9,41 \\
9,23 \\
10,45 \\
9,95 \\
9,48 \\
9,78 \\
10,82 \\
8,02 \\
11,37 \\
9,90 \\
9,33 \\
8.33 \\
8,08 \\
9,59 \\
9,95 \\
9,24 \\
7,81 \\
7,63\end{array}$ & 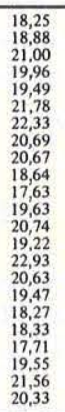 & $\begin{array}{l}0,03 \\
0,07 \\
0,04 \\
0,02 \\
0,04 \\
0,03 \\
0,04 \\
0,02 \\
0,04 \\
0,09 \\
0,10 \\
0,06 \\
0,08 \\
0,04 \\
0,04 \\
0,04 \\
0,04 \\
0,05 \\
0,04 \\
0,14 \\
0,04 \\
0,04 \\
0,04\end{array}$ & 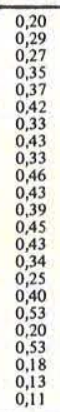 & 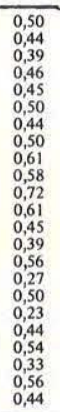 & $\begin{array}{c}100,00 \\
87,00 \\
86,00 \\
73,00 \\
61,00 \\
67,00 \\
67,00 \\
126,00 \\
86,00 \\
120.00 \\
105,00 \\
84,00 \\
98,00 \\
62,00 \\
53,00 \\
51,00 \\
141,00 \\
123,00 \\
103,00 \\
1551,00 \\
161.00 \\
51,00 \\
54,00\end{array}$ & 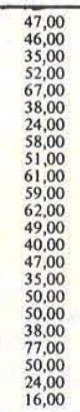 & 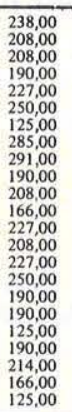 & 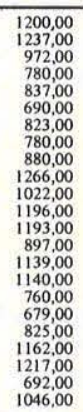 & $\begin{array}{l}450,00 \\
418,00 \\
293,00 \\
410,00 \\
337,00 \\
38,00 \\
424,00 \\
190,00 \\
144,00 \\
1440,00 \\
351,00 \\
203,00 \\
195,00 \\
122,00 \\
195,00 \\
50,00 \\
165,00 \\
100,00 \\
108,00 \\
330,00 \\
670,00 \\
1200,00 \\
955,00\end{array}$ \\
\hline GRUPO 08 & $(\%)$ & (\%) & (\%) & $\begin{array}{l}\mathrm{Mn} \\
(\%)\end{array}$ & (\%) & $\begin{array}{c}\text { Co } \\
(\mathrm{ppm})\end{array}$ & $\begin{array}{c}\mathrm{Ni} \\
(\mathrm{ppm})\end{array}$ & $\underset{(p p m)}{v}$ & $\underset{(\mathrm{ppm})}{\mathrm{Cu}}$ & $\underset{(\mathrm{ppm})}{\mathrm{Zn}}$ \\
\hline 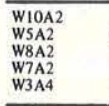 & $\begin{array}{r}, 8,88 \\
10,22 \\
8,88 \\
8,52 \\
9,01\end{array}$ & $\begin{array}{r}8,67 \\
9.50 \\
8,00 \\
7,78 \\
10,83 \\
10,83\end{array}$ & $\begin{array}{l}0.62 \\
0.37 \\
0.45 \\
0.97 \\
0.76\end{array}$ & $\begin{array}{l}0,15 \\
0.16 \\
0,29 \\
0,08 \\
0,38\end{array}$ & $\begin{array}{l}0,78 \\
0,722 \\
1,17 \\
1,11 \\
0,88\end{array}$ & $\begin{array}{l}54,00 \\
48,00 \\
67,00\end{array}$ & $\begin{array}{r}73,00 \\
65,00 \\
57,00 \\
28,00 \\
155,00\end{array}$ & & $\begin{array}{l}190,00 \\
222,00 \\
190,00 \\
160,00 \\
322,00\end{array}$ & $\begin{array}{l}135,00 \\
995,00 \\
173,00 \\
142,20 \\
245,00\end{array}$ \\
\hline $\begin{array}{l}\text { AMOSTRAS } \\
\text { NADO } \\
\text { AGRUPADAS }\end{array}$ & & (\%) & & (\%) & & (ppm) & $(\mathrm{ppm})$ & & (ppm) & (ppm) \\
\hline 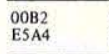 & & & & $\begin{array}{l}0.47 \\
0.08\end{array}$ & & $\begin{array}{l}60,00 \\
52,00\end{array}$ & $\begin{array}{r}91,00 \\
104,400\end{array}$ & & 551,00 & $\begin{array}{l}84,00 \\
101,00\end{array}$ \\
\hline
\end{tabular}

